\title{
Surfactant Quantity and Composition during Recovery from Hyaline Membrane Disease
}

\author{
J. CRAIG JACKSON, SUSAN PALMER, WILLIAM E. TRUOG, THOMAS A. STANDAERT, \\ JANET H. MURPHY, AND W. ALAN HODSON \\ Department of Pediatrics, University of Washington School of Medicine, Seattle, Washington 98195
}

\begin{abstract}
The appearance of phosphatidylglycerol in the tracheal wash of infants with hyaline membrane disease (HMD) has been reported to be associated with clinical signs of recovery. We analyzed lung tissue and bronchoalveolar lavage surfactant in an animal model of HMD to determine whether phosphatidylglycerol or some other component is necessary for recovery. The amount and composition of phospholipid (PL) was determined in the premature Macaca nemestrina monkey (140 days' gestation) during an acute stage of HMD, and in two stages of recovery. These changes were compared to observations made in healthy premature controls (140 days), gestational age-matched fetuses (140 days), and fetuses of 150 days' gestation (term = 168 days). The amount of PL and its surfactant composition in lung homogenates of the right lower lobe and in lavage of the excised left lung was determined. Compared to 140-day fetuses, the healthy controls had a several-fold increase in lavage PL and disaturated phosphatidylcholine (DSPC) during the first few days of life $(p<0.05)$. Prior to recovery, animals with HMD had no such increase in lavage PL or DSPC and demonstrated poor deflation stability. Recovery was associated with increased tissue and lavage PL $(p<0.05)$ and increased fractions of phosphatidylinositol and DSPC ( $p$ $<0.05$ ), but not phosphatidylglycerol. The tissue compositional changes observed during recovery reflected maturational changes observed in the fetal animals studied at 10 days' greater gestational age. Increases in lavage DSPC beyond $2 \mathrm{mg} / \mathrm{g}$ dry lung were not associated with further increases in deflation stability. We conclude that increases in DSPC and phosphatidylinositol are associated with recovery from HMD but phosphatidylglycerol does not appear necessary for either improved deflation stability or clinical recovery. (Pediatr Res 20: 1243-1247, 1986)
\end{abstract}

\section{Abbreviations}

HMD, hyaline membrane disease

PL, phospholipid

PC, phosphatidylcholine

DSPC, disaturated phosphatidylcholine

UPC, unsaturated phosphatidylcholine

PG, phosphatidylglycerol

PI, phosphatidylinositol

PE, phosphatidylethanolamine

PS, phosphatidylserine

SPH, sphingomyelin

Received March 20, 1986; accepted July 11, 1986.

Correspondence and reprint address J. Craig Jackson, M.D., Pediatrics RD-20, University of Washington, Seattle, WA 98195.

This study was supported by Grants NIH-HL-19187 (Pediatric Pulmonary SCOR), RR-00166 (Regional Primate Research Center at the University of Washington), NIH-HL-01205 (Research Career Development award to W.E.T.), and a research training grant from the American Lung Association (J.C.J)
TLC, total lung capacity (in vivo)

$\mathbf{V}_{\text {max }}$, maximal lung volume (postmortem)

ANOVA, one-way analysis of variance

It is not known whether or not recovery from HMD is contingent on the production of a minimal amount of surface active material and, if so, how much is needed. Although it has been proposed that certain surfactant components, such as PG, may be necessary for recovery (1), studies on pulmonary surfactant composition in human infants during recovery have been limited to examination of tracheal wash. Because of the low mortality during recovery from HMD, it has been impossible to determine the changes in tissue production of PL during recovery or to relate these changes to PL present in the alveolar lavage. The appropriate balance of tissue and alveolar quantities, and the optimal composition of surfactant components needed for recovery, remain ill defined.

In order to examine the recovery process in HMD by in vivo methods not feasible in humans, we have previously studied nonhuman primates with experimental HMD (2). TLC and deflation stability were measured serially in animals recovering from HMD and in premature controls; deflation stability improved over the first $12 \mathrm{~h}$ of life even though TLC declined and remained low for the first 2 days. These observations caused us to investigate the timing and role of surfactant synthesis and secretion in the recovery process.

In the present study, we tested the hypothesis that recovery from experimental HMD begins only after an increase in the synthesis and secretion of PL rich in the surfactants PG and DSPC. The PL quantity and composition present during the development of HMD and during two stages of recovery were examined in the monkey model. Animals delivered at the same gestation that did not develop HMD served as controls. In order to determine the contribution due to air breathing, fetuses at the same gestation were sacrificed for comparison. In order to compare the changes in PL quantity and composition during recovery from HMD with the expected changes of in utero lung maturation, fetuses at a later point in gestation were also studied.

\section{METHODS}

The study was conducted using Macaca nemestrina primates delivered prematurely by hysterotomy without preceding labor (3). Fetuses were killed at 140 or 150 days' gestation (term $=168$ days) by infusion of a lethal dose of pentobarbital $(150 \mathrm{mg} / \mathrm{kg})$ into the umbilical vein prior to the onset of air breathing. Additional animals delivered at 140 days' gestation were resuscitated by endotracheal intubation and ventilated with supplemental oxygen. These animals were kept under a radiant warmer, given intravascular fluids and glucose, and provided medical and 
nursing care appropriate for prematurely delivered humans. The TLC was measured by nitrogen washout (4) at 2, 6, 12, and 24 $\mathrm{h}$ of age, and at least daily thereafter, in order to assess the stage of recovery; these data are reported elsewhere (2).

HMD was diagnosed by the presence of a reticulogranular pattern and air bronchograms on the chest radiograph at $3 \mathrm{~h}$ of age. The animals were mechanically ventilated and given supplemental oxygen as needed for respiratory acidosis and hypoxemia. Animals with HMD that developed progressive hypoxemia, acidosis, and hypotention refractory to conventional therapy were sacrificed before recovery and constitute the "no recovery" group. The remaining animals with HMD were randomly chosen for sacrifice either "early in recovery" or "after recovery"; the former group consisted of animals demonstrating clinical improvement (reduced requirements for supplemental oxygen and ventilation) and an increase in TLC to $50 \%$ of control values, whereas the latter group included only those animals no longer requiring assisted mechanical ventilation and with an increase in TLC to normal (2). Healthy premature animals that did not develop clinical or radiologic evidence of HMD served as gestationmatched "controls."

Postmortem measurements. Immediately after the intravascular infusion of a lethal dose of pentobarbital, the lungs were excised, separated, and weighed. Freshly weighed portions of right lung were analyzed for dry weight, DNA, and protein (5). Lipids were extracted from lung homogenates; determination of lipid phosphorus quantity (6) allowed calculation of total PL. PL distributions were initially determined by methods previously reported from our laboratories (7). Briefly, lipid extracts were fractionated by column chromatography on diethylaminoethyl cellulose (8) into three fractions. If recovery of lipid phosphorus was within $10 \%$ of the amount placed on the column, the PL fractions were further separated into individual components by thin-layer chromatography in duplicate; these measurements were accepted only if the recoveries were at least $90 \%$. Because this procedure required more lipid than was available in lavage extracts from animals in the fetal and HMD-no recovery groups, the one dimension thin-layer chromatographic methods of Fine and Sprecher (9) were adapted. This technique clearly separated the six major PL components (PC, PE, SPH, PI, PS, and PG) on soft Silica Gel G plates with preabsorbant spotting zone (Supelco, Bellefonte, PA). The plates were impregnated with $1.5 \%$ boric acid and the solvent system was $\mathrm{CHCl}_{3}: \mathrm{MeOH}: \mathrm{NH}_{4} \mathrm{OH}$, $120: 75: 8, \mathrm{v} / \mathrm{v}$. The lipids were identified by comigration with known standards (Supelco, Bellefonte, PA) on each plate. Results from the two techniques were similar when extracts from the same animal were measured. The disaturated component of PC (DSPC) was determined with osmium tetroxide (10); recoveries of added 1,2-di $\left(1-{ }^{14} \mathrm{C}\right)$ palmitoyl-phosphorylcholine (Applied Science, State College, PA) were consistently greater than $90 \%$.

The left lung was degassed and then slowly inflated with air to $35 \mathrm{~cm} \mathrm{H} \mathrm{H}_{2} \mathrm{O}$ pressure in order to provide as full an inflation as possible without causing air leak. The maximal lung volume on the third inflation was corrected for the proportion of total lung weight represented by the left lung and defined as $V_{\text {max }}$. A static pressure-volume curve of the third deflation was recorded on an $x-y$ plotter; the fraction of lung volume retained at $10 \mathrm{~cm} \mathrm{H}_{2} \mathrm{O}$ was assumed to reflect the influence of alveolar surface tension forces upon deflation (11) and was used as an index of deflation stability. The left lung was then lavaged with room temperature saline five times; the wash material was pooled and centrifuged to remove cells and debris (12). The supernatant was analyzed for lipid phosphorus content and PL composition by methods outlined above.

Statistical methods. Multiple group comparisons were performed by ANOVA. For variables identified as significant by ANOVA, unpaired two-tailed $t$ tests were used to compare the 140-day fetuses and the HMD-no recovery groups to other groups. Where data did not appear to be normally distributed, the nonparametric Mann-Whitney test was applied. A $p$ value of less than 0.05 was considered significant. Data are presented as the mean $\pm 1 \mathrm{SD}$.

\section{RESULTS}

Eleven fetuses were studied, seven at 140 days' and four at 150 days' gestation. Of the 23 liveborn animals, HMD was diagnosed in 17. All of the animals with HMD required mechanical ventilation and supplemental oxygen because of progressive respiratory acidosis and hypoxemia. Nine animals with HMD died or were sacrificed before recovery and comprise the "no recovery" group. Of the eight animals that recovered from HMD, four were sacrificed "early in recovery," and three satisfied the criteria for "after recovery"; one recovering animal did meet the criteria of clinical and lung volume improvements at 5 days of age and was therefore excluded from analysis. Six premature animals which required only transient supplemental oxygen served as gestationmatched "controls." Serial TLC measurements in the controls and animals recovering from HMD are shown in Figure 1.

Lung size and weight. Although the mean birth weight of the 150-day fetuses was $12 \%$ greater than that of those delivered at 140 days $(p<0.05)$, there were no significant differences in lung weights; total lung DNA, protein, and PL, or size of $V_{\max }$ (Table 1). Air breathing for 4 days by the healthy controls was associated with a $28 \%$ decline in fresh lung weight $(p<0.05)$ compared to gestation-matched fetuses; the total lung PL was $41 \%$ greater ( $p$ $<0.05$ ) but there was no change in dry lung weight, DNA, protein, or $V_{\max }$. The animals with "no recovery" from HMD had no postnatal decline in fresh lung weight as was noted in healthy controls; the dry lung weight of the animals with HMD was $47 \%$ greater than the gestation-matched fetuses $(p<0.001)$ and the lung protein was $44 \%$ greater $(p<0.05)$. The total lung PL was no different than that in the 140-day fetuses but there was a greater than $50 \%$ reduction in $\mathrm{V}_{\max }(p<0.0001)$.

The lung dry weight of the "after recovery" group was greater than in the "no recovery" group $(p<0.05)$, although there were no changes in fresh lung weight; this increase was associated with increased tissue protein and total lung PL $(p<0.05)$. As expected from the experimental protocol which defined "early in recovery" and "after recovery" by in vivo measurements of TLC, the postmortem $\mathrm{V}_{\max }$ was 3-fold greater in the "after recovery" group $(p<0.0001)$.

$P L$ quantity and composition. Since variables such as fresh

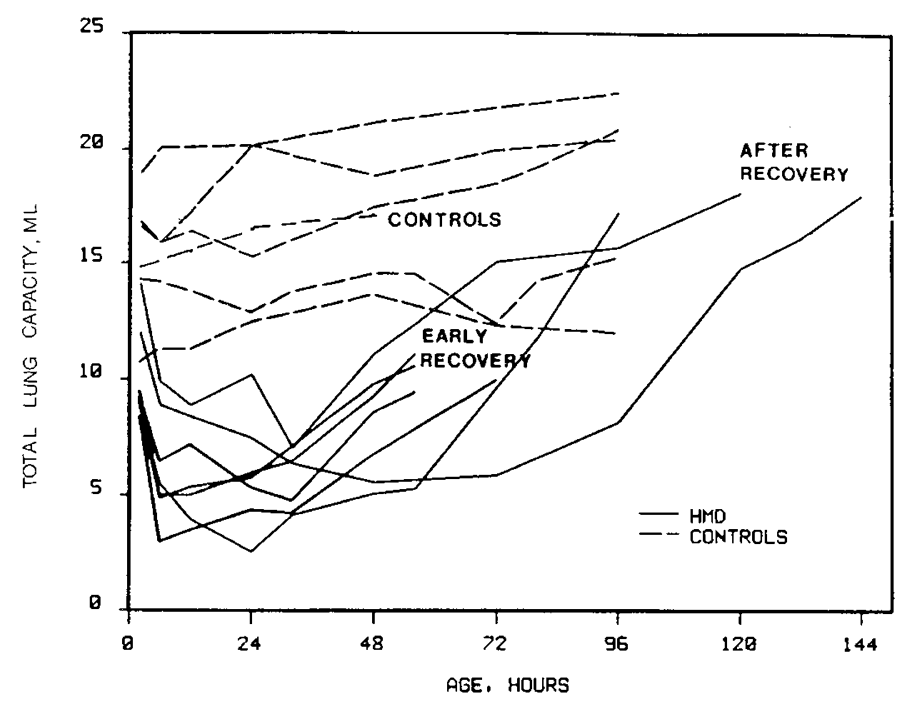

Fig. 1. Serial measurements of TLC. Animals recovering from HMD were sacrificed for postmortem studies either early in recovery when TLC was half of normal, or after recovery when TLC had returned to normal. Healthy premature controls were sacrificed at an age intermediate between the two recovering HMD groups. 
Table 1. Lung wt, dry wt composition, and volume*

\begin{tabular}{lcccccc}
\hline & $\begin{array}{c}\text { Fetal } \\
\text { 140-day } \\
\text { gestation }\end{array}$ & $\begin{array}{c}\text { Fetal } \\
\text { 150-day } \\
\text { gestation }\end{array}$ & $\begin{array}{c}\text { Healthy controls } \\
3-4 \text { days }\end{array}$ & $\begin{array}{c}\text { HMD-no recovery } \\
\text { 1 day }\end{array}$ & $\begin{array}{c}\text { HMD-early in recovery } \\
\text { 2-3 days }\end{array}$ & $\begin{array}{c}\text { HMD-after recovery } \\
4-6 \text { days }\end{array}$ \\
\hline$n$ & 7 & 4 & 6 & 9 & 4 & 3 \\
Gestation (day) & $140 \pm 1$ & $150 \pm 1 \dagger$ & $142 \pm 2$ & $138 \pm 2$ & $140 \pm 2$ & $139 \pm 1$ \\
Birth wt (g) & $360 \pm 39$ & $405 \pm 22 \ddagger$ & $362 \pm 44$ & $354 \pm 37$ & $390 \pm 33$ & $388 \pm 30$ \\
Fresh lung wt (g) & $7.0 \pm 1.2$ & $7.6 \pm 1.4$ & $5.0 \pm 1.1 \ddagger$ & $7.2 \pm 1.4$ & $6.5 \pm 0.4$ & $7.2 \pm 0.5$ \\
Dry lung wt (g) & $0.64 \pm 0.07$ & $0.69 \pm 0.09$ & $0.78 \pm 0.16$ & $0.94 \pm 0.23 \S$ & $1.06 \pm 0.06$ & $1.19 \pm 0.10 \|$ \\
DNA (mg) & $43 \pm 4$ & $43 \pm 8$ & $51 \pm 8$ & $52 \pm 20$ & $56 \pm 10$ & $60 \pm 9$ \\
PL (mg) & $63 \pm 9$ & $84 \pm 27$ & $89 \pm 16 \neq$ & $75 \pm 22$ & $107 \pm 3$ & $148 \pm 20 \|$ \\
$\quad$ Protein (mg) & $413 \pm 96$ & $416 \pm 64$ & $544 \pm 129$ & $593 \pm 191 \ddagger$ & $681 \pm 39$ & $760 \pm 52 \|$ \\
$V_{\max }$ (ml) & $15.1 \pm 2.8$ & $18.4 \pm 3.5$ & $19.9 \pm 6.6$ & $6.7 \pm 3.2 \dagger$ & $11.2 \pm 1.5$ & $20.8 \pm 5.6 \uparrow$ \\
\hline
\end{tabular}

* Excluding the 150-day fetuses, the groups were matched for gestational age and birth weight. Healthy controls had reduced fresh lung weight and all HMD groups had greater dry lung weight than the 140-day fetuses. Animals with HMD had greater lung protein; prior to recovery, $V_{\text {max }}$ was less than normal.

$\dagger$ Different from fetal-140 days, $p<0.0001$

$\ddagger$ Different from fetal-140 days, $p<0.05$.

$\S$ Different from fetal-140 days, $p<0.001$.

$\|$ Different from HMD-no recovery, $p<0.05$.

ๆ Different from HMD-no recovery, $p<0.0001$.

Table 2. Lung tissue PL, DSPC, and PL composition*

\begin{tabular}{|c|c|c|c|c|c|c|}
\hline & $\begin{array}{c}\text { Fetal 140-day } \\
\text { gestation }\end{array}$ & $\begin{array}{l}\text { Fetal } 150 \text {-day } \\
\text { gestation }\end{array}$ & $\begin{array}{c}\text { Healthy controls } \\
3-4 \text { days }\end{array}$ & $\begin{array}{c}\text { HMD-no recovery } \\
1 \text { day }\end{array}$ & $\begin{array}{l}\text { HMD-early in recovery } \\
2-3 \text { days }\end{array}$ & $\begin{array}{l}\text { HMD-after recovery } \\
4-6 \text { days }\end{array}$ \\
\hline $\begin{array}{l}\text { Lung PL (mg/g dry } \\
\text { lung) }\end{array}$ & $98 \pm 4$ & $119 \pm 26$ & $114 \pm 17$ & $79 \pm 10 \dagger$ & $101 \pm 4$ & $124 \pm 7 \ddagger$ \\
\hline $\begin{array}{l}\text { Lung DSPC (mg/g } \\
\text { dry lung) }\end{array}$ & $19 \pm 3$ & $32 \pm 12$ & $28 \pm 11$ & $12 \pm 3 \S$ & $19 \pm 3$ & $27 \pm 21$ \\
\hline$\%$ DSPC & $19 \pm 3$ & $26 \pm 59$ & $26 \pm 6 \pi$ & $15 \pm 39$ & $19 \pm 2$ & $22 \pm 1 \|$ \\
\hline$\%$ UPC & $28 \pm 2$ & $27 \pm 2$ & $27 \pm 4$ & $30 \pm 2$ & $28 \pm 2$ & $31 \pm 2$ \\
\hline$\% \mathrm{PE}$ & $20 \pm 3$ & $14 \pm 7$ & $18 \pm 2$ & $23 \pm 2$ & $20 \pm 3$ & $19 \pm 1^{* *}$ \\
\hline$\% \mathrm{SPH}$ & $12 \pm 1$ & $10 \pm 1$ & $11 \pm 1$ & $12 \pm 1$ & $10 \pm 1$ & $9 \pm 1 \|$ \\
\hline$\% \mathrm{PI}$ & $5.5 \pm 0.4$ & $6.8 \pm 0.3 \dagger$ & $6.6 \pm 1.1$ & $5.4 \pm 0.5$ & $7.5 \pm 1.0$ & $8.2 \pm 0.8^{* *}$ \\
\hline$\%$ PS & $7.4 \pm 1.1$ & $6.4 \pm 0.9$ & $6.5 \pm 1.2$ & $7.4 \pm 1.4$ & $4.8 \pm 1.5$ & $5.3 \pm 0.3^{* *}$ \\
\hline$\% \mathrm{PG}$ & $0.7 \pm 0.5$ & $1.6 \pm 1.2$ & $0.7 \pm 0.5$ & $0.8 \pm 0.3$ & $0.5 \pm 0.1$ & $0.6 \pm 0.4$ \\
\hline
\end{tabular}

* Prior to recovery, HMD is associated with reduced tissue PL and DSPC. After recovery, PL and DSPC, and the fractions of PL represented by DSPC and PI increase, whereas \% PE, \%SPH, and \%PS decline.

$\dagger$ Different from fetal-140 days, $p<0.0001$.

$\ddagger$ Different from HMD-no recovery, $p<0.001$.

$\S$ Different from fetal-140 days, $p<0.001$.

$\|$ Different from HMD-no recovery, $p<0.0001$.

II Different from fetal- 140 days, $p<0.05$.

** Different from HMD-no recovery, $p<0.05$.

lung weight, dry lung weight, lung protein, and lung volume were significantly affected by gas ventilation, the development of HMD, or recovery from HMD, no denominator for comparison of PL or DSPC quantity is entirely satisfactory. The data in Tables 2 and 3 are expressed as amounts per g dry lung, since this measurement is technically reliable and tends to underestimate rather than overestimate the changes in PL observed with recovery. In the two fetal groups, lung tissue PL and DSPC per $\mathrm{g}$ dry lung were not statistically different (Table 2); however, there were significant changes in the fractional components of lung tissue PL represented by DSPC $(p<0.05)$ and PI $(p<$ $0.0001)$. There were no significant changes in the amount or component distributions of PL recoverable from lung lavage (Table 3), although the trends toward greater \%DSPC and \%PI reflected the gestationally related changes occurring in lung tissue.

During the 4 days of postnatal life in healthy controls, lung tissue PL and DSPC per g dry lung did not increase significantly but the \%DSPC did $(p<0.05)$. However, air breathing by the controls was associated with a several-fold increase in the amount of PL and DSPC recoverable from the lung lavage $(p<0.05)$.
The composition of the PL in the lung lavage was no different than in fetuses at 140 days' gestation except for an increase in the fraction of PI $(p<0.05)$.

The animals with no recovery from HMD had significantly less lung tissue PL $(p<0.0001)$ and DSPC $(p<0.001)$ per $g$ dry lung than fetuses at 140 days' gestation. The composition of the tissue PL was similar to the fetuses except for a lesser fraction of DSPC $(p<0.05)$. Unlike the healthy air-breathing controls, there was no increase in PL recoverable in the lung lavage. The component distribution of the lavage PL revealed that failure to recover from HMD is associated with a reduced fraction of DSPC $(p<0.001)$ and increased fractions of SPH $(p<0.0001)$ and $\mathrm{PE}(p<0.05)$.

There were substantial changes in the amount and composition of both tissue and lavage PL during recovery. The "after recovery" group had $57 \%$ more lung tissue PL $(p<0.001)$ and twice as much DSPC $(p<0.0001)$ per $\mathrm{g}$ dry lung as the "no recovery" group. There were also significant increases in \% DSPC and \%PI, and decreases in \%PE, \%SPH, and \%PS $(p<0.05)$. The amounts of PL and DSPC recoverable from the lavage increased several-fold after recovery $(p<0.05)$; the fractions of 
Table 3. Lavage PL, DSPC, and PL composition*

\begin{tabular}{lcccccc}
\hline & $\begin{array}{c}\text { Fetal 140-day } \\
\text { gestation }\end{array}$ & $\begin{array}{c}\text { Fetal 150-day } \\
\text { gestation }\end{array}$ & $\begin{array}{c}\text { Healthy controls } \\
\text { 3-4 days }\end{array}$ & $\begin{array}{c}\text { HMD-no recovery } \\
\text { 1 day }\end{array}$ & $\begin{array}{c}\text { HMD-early in recovery } \\
2-3 \text { days }\end{array}$ & $\begin{array}{c}\text { HMD-after recovery } \\
4-6 \text { days }\end{array}$ \\
\hline $\begin{array}{l}\text { Lavage PL (mg/g dry } \\
\text { lung) }\end{array}$ & $3.4 \pm 2.7$ & $4.5 \pm 2.1$ & $27.4 \pm 18.2 \dagger$ & $1.8 \pm 0.6$ & $8.1 \pm 3.5$ & $16.8 \pm 3.3 \ddagger$ \\
$\begin{array}{l}\text { Lavage DSPC (mg/g } \\
\text { dry lung) }\end{array}$ & $1.8 \pm 1.2$ & $2.2 \pm 0.9$ & $13.0 \pm 8.9 \dagger$ & $0.5 \pm 0.2$ & $3.0 \pm 1.6$ & \\
\% DSPC & $44 \pm 8$ & $50 \pm 7$ & $47 \pm 5$ & $25 \pm 10 \S$ & $35 \pm 5$ & $6.6 \pm 1.2 \ddagger$ \\
\% UPC & $22 \pm 8$ & $25 \pm 8$ & $32 \pm 3$ & $29 \pm 5$ & $32 \pm 1$ & \\
\% PE & $4.4 \pm 3.0$ & $3.3 \pm 1.4$ & $4.1 \pm 1.5$ & $12 \pm 3 \dagger$ & $8.6 \pm 1.5$ & $35 \pm 4 \ddagger$ \\
\% SPH & $4.5 \pm 2.8$ & $1.9 \pm 0.8$ & $2.3 \pm 1.2$ & $15 \pm 4 \|$ & $8.7 \pm 3.1$ & $7.2 \pm 1.1 \ddagger$ \\
\% PI & $4.8 \pm 2.4$ & $6.6 \pm 1.1$ & $8.6 \pm 1.2 \dagger$ & $4.2 \pm 1.7$ & $5.7 \pm 0.9$ & $5.2 \pm 0.8 \ddagger$ \\
\% PS & $1.4 \pm 0.8$ & $2.0 \pm 1.8$ & $0.9 \pm 0.4$ & $2.0 \pm 0.6$ & $1.4 \pm 1.0$ & $8.3 \pm 0.7 \ddagger$ \\
\% PG & $0.5 \pm 0.5$ & $0.8 \pm 0.6$ & $0.4 \pm 0.3$ & $1.6 \pm 0.5$ & $0.5 \pm 0.5$ & $1.5 \pm 0.2$ \\
\hline
\end{tabular}

* Healthy controls had increased lavage PL, DSPC, and \%PI. Prior to recovery, \%DSPC was lower than in gestation-matched fetuses and \%PE and \%SPH were greater. After recovery, PL, DSPC, \%DSPC, and \%PI were increased, and \% PE and \%SPH declined.

$\uparrow$ Different from fetal- 140 days, $p<0.05$.

$\$$ Different from HMD-no recovery, $p<0.05$.

$\S$ Different from fetal- 140 days, $p<0.001$.

$\|$ Different from fetal-140 days, $p<0.0001$.

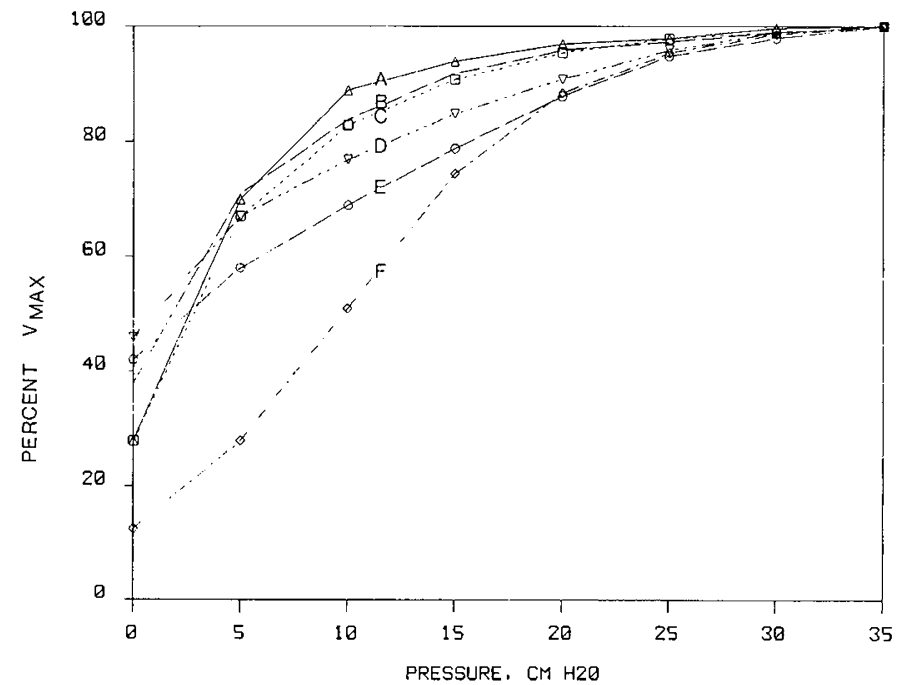

Fig. 2. Postmortem pressure-volume deflation curves. $A$, HMD-after recovery; $B$, controls; $C$, HMD-early in recovery; $D$, fetal- 150 days; $E$, fetal-140 days; $F$ HMD-no recovery. The $\% \mathrm{~V}_{\max }$ at a pressure of $10 \mathrm{~cm}$ $\mathrm{H}_{2} \mathrm{O}$ was lower in the HMD-no recovery group than in controls, the early recovery group, or the after recovery group $(p<0.001)$. Deflation stability after recovery was not significantly different than early in recovery.

PL represented by DSPC and PI also increased $(p<0.05)$. Except for \%PS, changes in lavage PL fractions mirrored changes in lung tissue.

Deflation stability. The deflation pressure-volume curves for the six groups of animals are shown in Figure 2. The percent of $\mathrm{V}_{\max }$ present at $10 \mathrm{~cm} \mathrm{H} \mathrm{H}_{2} \mathrm{O}$ pressure $\left(\% \mathrm{~V}_{10}\right)$ for the HMD "no recovery" group $(51 \pm 11)$ was significantly lower $(p<0.001)$ than in controls $(84 \pm 7)$, the "early recovery" group $(83 \pm 2)$, or the "after recovery" group $(87 \pm 3)$. Even though the "early recovery" group had reduced $V_{\max }$ and lesser amounts of lavage surfactants than the "after recovery" or control groups, the lungs had normal deflation stability.

By plotting $\% \mathrm{~V}_{10}$ against lavage DSPC amounts (Fig. 3), an estimate of the minimum amount of this surface active material associated with normal deflation stability was made. Lungs with greater than $2 \mathrm{mg}$ DSPC per g dry lung had deflation stability of greater than $75 \%$.

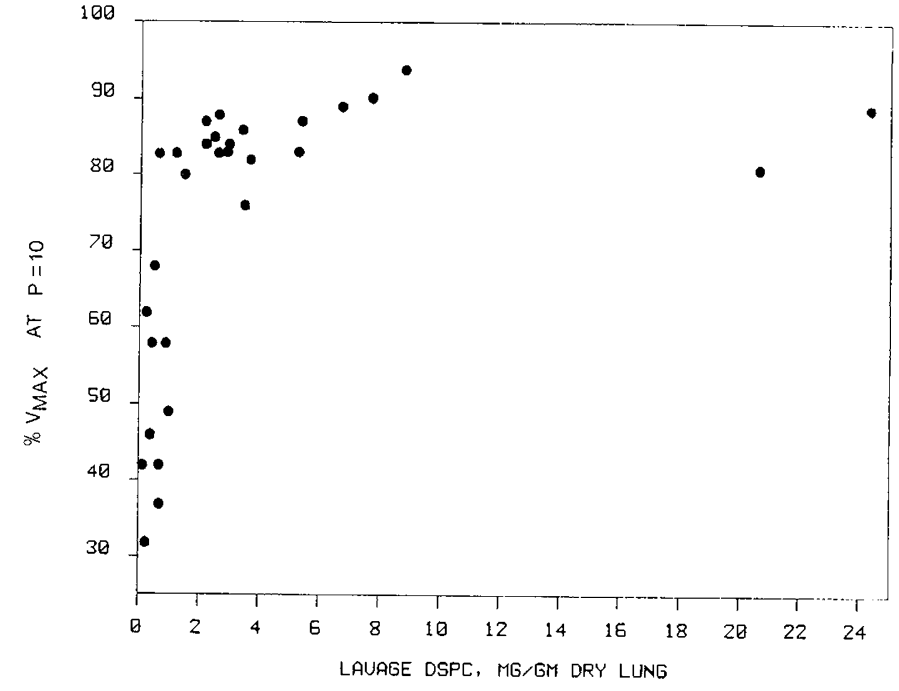

Fig. 3. Deflation stability as a function of lavage DSPC quantity. Additional DSPC beyond $2 \mathrm{mg} / \mathrm{g}$ dry lung does not further improve deflation stability ( $\% \mathrm{~V}_{\max }$ remaining at $10 \mathrm{~cm} \mathrm{H}_{2} \mathrm{O}$ pressure).

\section{DISCUSSION}

In order to compare lung constituents in animals with different size lungs, it is common to express measurements relative to body weight or to lung wet weight, dry weight, or maximal volume. Because of the substantial alterations in lung water and compliance at birth as well as in lung injury, comparisons based on lung wet weight or $\mathrm{V}_{\max }$ are inappropriate in this study. Since the birth weight of the older gestation fetuses was significantly different than the 140-day animals, this is also an unacceptable denominator. In order to allow the phospholipid measurements to be compared to data from other studies, quantities of PL and DSPC were expressed as amounts per g dry lung in Table 2, although changes in lung dry weight due to HMD seriously compound interpretation.

In common with human infants dying of HMD (13), $M$. nemestrina monkeys with unresolved HMD have reduced tissue quantities of PL and surfactants such as DSPC when these data are expressed as amounts per $g$ dry lung weight. The apparent decline from fetal values was due to an increase in lung dry weight partly as a result of increased lung tissue protein; the quantity of PL in lung tissue expressed in absolute amounts was 
unchanged. The amount of PL present in the lung lavage of animals with HMD did not increase with air breathing as it did in healthy premature controls; the small amount of PL released was deficient in DSPC and rich in PE and SPH, compounds that are not effective surfactants. As in humans with HMD, insufficient quantity and the abnormal composition of lung surfactant in these animals are associated with reduced deflation stability.

Changes in lung tissue surfactant during recovery from HMD cannot be systematically studied in humans because of the very low mortality in recovering infants. The degree to which tracheal aspirates reflect alveolar lavage PL quantity or composition is uncertain and the findings in infants with respiratory disorders may be nonspecific (14). Previous studies performed during recovery from HMD have reported conflicting results. For instance, the \%DSPC in tracheal aspirates of human infants with HMD had been reported to increase over the 1st wk of life (15), but others could detect no change during this same interval (16). In the current study, these uncertainties were circumvented by the use of an animal model that could be electively sacrificed at different stages of recovery for postmortem bronchoalveolar lavage.

Because deflation stability improves during resolution of HMD, surfactant amount must increase and/or quality must improve to some minimal level. In the monkey model of HMD, recovery is associated with increased lung tissue PL (in absolute or relative amounts) and changes in the composition of PL to favor DSPC and PI, at the expense of PE, SPH, and PS. The amount of PL in the lavage increases several-fold during recovery, and the fractions represented by DSPC and PI are greater.

The direction of changes in the ratio of DSPC to SPH during recovery in these animals mirrors maturational changes in the lecithin/SPH ratio observed in human amniotic fluid during the last weeks of human gestation; delivery prior to an increase in this ratio is associated with an increased risk of HMD (17). The present study suggests that disaturated lecithin (DSPC) may play an important role not only in the pathogenesis of HMD but also in recovery from the disease.

The findings of this study conflict with previously published observations about the relative importance of the acidic phospholipid components PG and PI in the occurrence of HMD and during the processes of recovery. The fraction of PI in human amniotic fluid PL declines during the final $5 \mathrm{wk}$ before delivery, whereas the PG fraction increases (18). PG appears to be an important modifier of surfactant function (19), and its deficiency in amniotic fluid is associated with an increased incidence of HMD $(20,21)$. PG is undetectable in the tracheal effluent of human infants with HMD prior to recovery, but its appearance coincides with clinical improvement $(1,15,16)$. Yet in the present study, there were significant increases in \%PI, but not $\% \mathrm{PG}$, in both lung tissue and lavage during recovery from HMD. Recovery from experimental HMD did not appear to depend on increases in \% PG since lung volumes and deflation stability in the recovered animals were normal.

Changes in the ratio of $\mathrm{PG}$ to PI may be a reflection of substrate availability rather than a critical maturational event. Animals fed myoinositol rather than glucose have a marked reduction in surfactant PG and an increase in PI (22) yet PG-deficient surfactant functions normally $(22,23)$. At the gestational age of the animals in this study, high fetal levels of inositol may have blocked phosphatidyltransferase, the enzyme responsible for PG synthesis; this possibility is supported by evidence that fetal rhesus monkeys do not normally synthesize PG before 155 days' gestation (24). The failure of PG to substitute for PI during the recovery phase when the only nutrient given was intravenous glucose is unclear.

The precise mechanisms responsible for recovery from HMD remain obscure. It should not be assumed that changes in surfactant quantity and composition lead directly to resolution of the disease. In fact, deflation stability returns to normal quite early in recovery when the animals are still clinically ill and lung volumes remain decreased; further increases in lung tissue and lavage surfactants are not associated with additional improvements in lung stability. The quantity of lavage DSPC associated with normal deflation stability in the present study, $2 \mathrm{mg} / \mathrm{g}$ dry lung, is quantitatively similar to the amount present in 1-monthold term monkeys, $2.9 \pm 0.5 \mathrm{mg} / \mathrm{g}$ dry lung (25), but is only a small fraction of the amount normally present in the first few days after birth. Further studies are needed to determine the physiologic significance of this apparent "surplus" of surfactant in normal and recovering infants.

\section{REFERENCES}

1. Hallman M, Feldman BH, Kirkpatrick E, Gluck L 1977 Absence of phosphatidylglycerol (PG) in respiratory distress syndrome in the newborn. Pediat Res 11:714-720

2. Jackson $\mathrm{IC}_{\mathrm{C}}$, Standaert TA, Truog WE, Murphy JH, Palmer S, Chi EY, Woodrum DE, Watchko JF, Hodson WA 1985 Changes in lung volume and deflation stability in hyaline membrane disease. J Appl Physiol 59:17831789

3. Prueitt JL, Palmer S, Standaert TA, Luchtel DL, Murphy JH, Hodson WA 1979 Lung development in the fetal primate Macaca nemestrina. III. HMD. Pediatr Res 13:654-659

4. Standaert TA, LaFramboise WA, Tuck RE, Woodrum DE 1985 The serial determination of lung volume in small animals by nitrogen washout. J Appl Physiol 58:205-210

5. Hodson WA, Palmer S, Blakely GA, Murphy JH, Woodrum DE, Morgan TE 1977 Lung development in the fetal primate Macaca nemestrina. I. Growth and compositional changes. Pediatr Res 11:1009-1014

6. Bartlett GR 1959 Phosphorus assay in column chromatography. $\mathrm{J}$ Biol Chem 234:466-468

7. Prueitt JL, Chi EY, Lagunoff D 1978 Pulmonary surface-active materials in the Chediac-Higashi syndrome. J Lipid Res 19:410-415

8. Rouser G, Kritchevsky G, Yamamoto A 1967 Column chromatography of phosphatides and glycolipids. In: Marinetti GV (ed) Lipid Chromatographic Analysis. Marcel Dekker. Inc, New York, pp 120-131

9. Fine JF, Sprecher S 1982 Unidimensional thin layer chromatography of phospholipids on boric acid impregnated plates. J Lipid Res 23:660-3

10. Mason RJ, Nellenbogen J, Clements JA 1976 Isolation of disaturated phosphatidylcholine with osmium tetroxide. J Lipid Res 17:281-284

11. Clements JA 1962 Surface phenomena in relation to pulmonary function. Physiologist 5:11-28

12. Kessler DL, Truog WE, Murphy JH, Palmer S, Standaert TA, Woodrum DE, Hodson WA 1982 Experimental hyaline membrane disease in the premature monkey: effects of antenatal dexamethasone. Am Rev Respir Dis 126:6269

13. Avery ME, Mead J 1959 Surface properties in relation to atelectasis and hyaline membrane diseases. Am J Dis Child 97:517

14. James DK, Chiswick ML, Harkes A, Williams M, Hallworth J 1984 Nonspecificity of surfactant deficiency in neonatal respiratory disorders. $\mathrm{Br}$ Med J 288:1635-1638

15. Jacob J, Gluck L, DiSessa T, Edwards D, Kulovich M, Kurlinski J, Merritt TA, Friedman WF 1980 The contribution of PDA in the neonate with severe RDS. J Pediatr 96:79-87

16. Bose CL, Richardson P, Wood B, Gonzalez F, King J 1984 Phospholipids in tracheal effluent from infants with severe respiratory distress syndrome. Am J Perinatol 1:208-213

17. Gluck L, Kulovich MV, Borer RC, Brenner PH, Anderson GG, Spellacy WN 1971 Diagnosis of the respiratory distress syndrome by amniocentisis. Am J Obstet Gynecol 109:440-445

18. Hallman M, Kulovich M, Kirkpatrick E, Sugarman RG, Gluck L 1976 Phosphatidylinositol and phosphatidylglycerol in amniotic fluid: Indices of lung maturity. Am J Obstet Gynecol 125:613-617

19. Hallman M, Gluck L 1976 Phosphatidylglycerol in lung surfactant. III. Possible modifier of surfactant function. J Lipid Res 17:257-262

20. Kulovich MV, Gluck L 1979 The lung profile. I. Normal pregnancy. Am J Obstet Gynecol 135:57-63

21. Whittle MJ, Wilson AI, Whitfield CR, Paton RD, Lowan RW 1982 Amniotic fluid phosphatidylglycerol and the lecithin/sphingomyelin ratio in the assessment of fetal lung maturity. Br J Obstet Gynaecol 89:727-732

22. Hallman M, Enhorning G. Possmayer F 1985 Composition and surface activity of normal and phosphatidylglycerol-deficient lung surfactant. Pediatr Res 19:286-292

23. Beppu OS, Clements JA, Goerke J 1983 Phosphatidylglycerol deficient lung surfactant has normal properties. J Appl Physiol 55:495-502

24. Perelman RH, Engle MJ, Kemnitz JW, Kotas RV, Farrell PM 1982 Biochemical and physiologic development of fetal rhesus lung. J Appl Physiol 53:230235

25. Jackson JC, Palmer S, Standaert TA, Murphy J, Truog WE, Woodrum DE, Hodson WA 1984 Developmental changes of surface active material in newborn non-human primates. Am Rev Respir Dis 129:A204(abstr) 